\title{
Survey-Based Analysis of Water Consumption Law in High-Rise Public Buildings and Water-Saving Performance of Pressure-Reducing Measures
}

\author{
Jinhui Zhao*, Xi Xie, Chentong Lin, Yao Sun, Ruiju Liu, Mengke Wu \\ College of Urban Construction, Nanjing Tech University, Nanjing, China \\ Email: ${ }^{\star}$ zhaojh@njtech.edu.cn
}

How to cite this paper: Zhao, J.H., Xie, X., Lin, C.T., Sun, Y., Liu, R.J. and Wu, M.K. (2017) Survey-Based Analysis of Water Consumption Law in High-Rise Public Buildings and Water-Saving Performance of Pressure-Reducing Measures. Journal of Geoscience and Environment Protection, 5, 189-203.

https://doi.org/10.4236/gep.2017.59014

Received: August 16, 2017

Accepted: September 17, 2017

Published: September 20, 2017

Copyright $\odot 2017$ by authors and Scientific Research Publishing Inc. This work is licensed under the Creative Commons Attribution International License (CC BY 4.0).

http://creativecommons.org/licenses/by/4.0/

(c) (i) Open Access

\begin{abstract}
Facing the contradiction of water scarcity and water wastage in most cities of China, this study aims at probing into the factors influencing water-use efficiency and assessing water-saving potential by adopting pressure control measures based on field survey conducted in 23 high-rise buildings in Suqian, China and laboratory tests. Results showed that per capita water consumption (PCWC) exceeding water consumption norms is common in these buildings. The hourly water consumption variation law is quite different among different types of buildings. These differences should be considered in designing building water supply systems to lower water and energy consumption. On the basis of correlation analysis, the order of factors influencing the PCWC follows average tap water pressure, per-capita building area, and building age, suggesting pressure management in high-rise buildings is a key water-saving measure. Field tests of outflow characteristics under different water pressures indicated that over-pressure outflow (OPO) is a common cause of water wastage in buildings, however, no branch pipe pressure control measures were found in all the surveyed buildings. Laboratory tests showed that branch pipe pressure-reducing measures can lower water consumption and improve the comfortability of use as well. Therefore, in addition to applying high efficiency water-saving devices, we strongly recommend that branch pipe pressure-reducing measures should be strictly implemented in designing new building water supply systems and reconstruction of existing old building water supply systems, thereby, promoting water, energy saving and development of green building.
\end{abstract}

\section{Keywords}

Water Saving, High-Rise Public Building, Over-Pressure Outflow, 
Pressure-Reducing Measure, Outflow Characteristics

\section{Introduction}

Along with rapid social-economic development and urbanization, water scarcity is increasingly becoming a crisis that constrains regional sustainable development. Identifying the means to coordinate the contradiction between economic development and water resource is an important issue that society is facing. Building, manufacturing, and transportation are the three main high energy-consuming industries. The building and construction sector in the Organization for Economic Cooperation and Development (OECD) countries consumes $25 \%-50 \%$ of the total energy used and $16 \%$ of the water used annually in the world [1] [2]. In the last century, water demand has increased at more than twice the rate of population growth. Water shortage is becoming one of the main constraints in many regions, even in regions that were traditionally considered water-ample, such as Europe and Japan [3]. With the ongoing efforts on industry water saving in China in the past decade, industry water utilization efficiency has improved significantly, industrial water consumption in some cities, such as Beijing and Nanjing, have continued to decrease. However, domestic water consumption has been increasing rapidly and exceeded the industrial water consumption already in some cities of China [4]. Identically, indoor domestic water demand (excluding garden irrigation and other external uses) in developed countries accounts for $30 \%-70 \%$ of the total urban water demand [3]. This increasing domestic water demand is due partly to the increasing population and living standards, as well as to water wastage caused by the lack of awareness on water saving. The existing research into building water use mainly considered water saving in residential buildings [5]. However, water consumption in public buildings is increasing rapidly [6] [7]. The existence of severe water wastage in public buildings should be noticed because water is free of charge to individual users. Moreover, an increasing number of high-rise buildings are undergoing construction for growing populations in limited city space in big cities of China. Generally, the per capita water consumption (PCWC) in high-rise buildings is higher than that in low-rise buildings because of the high water pressure needed. Studies on water consumption law and corresponding water-saving measures in high-rise public buildings have substantially practical meaning for the conservation of water and embodied energy in water [8].

Aimed at developing low water-consuming and low energy-consuming green buildings, research on reducing water consumption and embodied energy in building water supply systems has been conducted worldwide. Establishing a water reuse system and improving water use efficiency are two main engineering measures to reduce water consumption in buildings, whereas measures such as price strategies and water restriction strategies belong to management measures. 
Engineering measures are easier to accept by the public than management measures [9]. Rainwater and greywater are considered as the potential source water for reuse in building. Rainwater harvesting system in commercial, residential, and public buildings, as well as industries have been reported by many researchers [10] [11] [12]. Greywater reuse in buildings has also been introduced [13] [14]. Existing research on improving water use efficiency mainly focused on applying high-efficiency appliances and water-saving plumbing fixtures [9] [15] [16] [17] [18] [19]. In addition, water supply systems consume $1 \%$ - 4\% of electricity and are the largest single consumer in a city [20]. The specific energy consumed by water supply systems varied from $1.1-1.4 \mathrm{kWh} / \mathrm{m}^{3}$ in some Asian cities [21]. Approximately half of the energy was consumed by pumping system [22]. Therefore, saving water in buildings is saving energy, some studies have been carried out on investment feasibility analysis and embodied energy in water-saving strategy decision-making [8] [23] [24] [25] [26].

From the above studies, most research focused on establishing a water reuse systems and applying high-efficiency appliances to save water in buildings. Little research has been reported on water consumption influencing factors and the corresponding water-saving measures by optimizing design and operation of high-rise building water supply systems. For example, the adoption of high-efficiency appliances is considered as one of the best management practices for water conservation [27]. In fact, each water appliance has its rated flow which is the suitable flow rate to satisfy the stated purpose and to achieve a sense of comfort under rated pressure. However, water pressure in high-rise buildings always exceed the rated pressure of water appliances. This discrepancy causes the outflow of water appliance to exceed its rated flow, as flow rate is proportional to water pressure at water distribution points. This phenomenon is called "over-pressure outflow" (OPO), and is one of the main causes of water wastage in buildings, especially in high-rise buildings [28].

The Chinese standard "Code for Design of Building Water Supply and Drainage (GB 50015-2003, 2009 edition)" requires hydrostatic pressure at water distribution points to be lower than $0.45 \mathrm{MPa}$, otherwise, a zoned water supply system should be adopted to ensure water pressure at distribution points to be lower than $0.45 \mathrm{MPa}$. However, this pressure limitation is mainly intended to prevent damage to plumbing systems and plumb fixtures under high pressure, it has limited effect on OPO prevention. From the perspective of water saving, the Chinese national standard "Standard for Water Saving Design in Civil Building" (GB50555-2010) further recommends that pressure-reducing measures, such as branch pipe pressure-reducing valves (PRVs) should be adopted in high-pressure stories to reduce the pressure to below $0.2 \mathrm{MPa}$ in newly designed buildings. However, this clause is not a compulsory specification, therefore, it is not well implemented in the last few years. In addition, massive old buildings still face water wastage due to OPO. Thus far, the water-saving performance of branch pipe PRVs has not been reported in the literature, leading the public and even 
some designers to disregard its water-saving performance. According to the author's survey of 195 water distribution points in 23 existing public buildings, more than $95 \%$ of the testing points exceeded the rated pressure of $0.1 \mathrm{MPa}$ for faucets. More than $64.5 \%$ of the testing points exceeded the recommended maximum pressure limitation of $0.2 \mathrm{MPa}$ in GB50555-2010, and more than $12 \%$ of the testing points exceeded $0.45 \mathrm{MPa}$, which is the maximum pressure limitation recommended in GB 50015-2003 (2009 edition). This resulted 94\% of the 195 tested flow rates of single lever basin tap exceeded its rated flow rate and $62.5 \%$ of the 195 tested flow rates of water basin mixer tap exceeded its rated flow rate. Therefore, the performance of pressure management measures should be fully studied and highly valued to save water in buildings.

The objectives of this study are listed as follows:

1) To assess the current water consumption efficiency in high-rise public buildings. A total of 23 typical high-rise buildings with different use purposes, building heights, building ages, and management levels were selected to reflect water consumption under different conditions in Suqian City, China. The basic information of the 23 buildings and the corresponding two years of continuous water consumption data were collected for analysis.

2) To probe the outflow characteristics of water appliances and the factors that influence PCWC in building. Field tests were conducted in 195 floors in the 23 high-rise buildings to obtain the pressure-outflow data of different water appliances. Seven-day continuous daily water consumption data and two-day hourly water consumption data were also monitored. PCWC and its variation characteristics in different public buildings were analyzed based on the survey and the field tests. Moreover, the relation between water consumption and its influencing factors were studied through linear correlation analysis.

3) To make a further study of the water saving performance of branch pipe pressure reducing measures, field tests and laboratory tests were conducted to get the pressure-outflow characteristics of different water appliances and to quantitatively assess the water saving performance of branch pipe pressure reducing measures.

\section{Materials and Methods}

\subsection{Study Area}

Suqian city $\left(117^{\circ} 56^{\prime} \mathrm{E}-119^{\circ} 10^{\prime} \mathrm{E}\right.$ and $\left.33^{\circ} 8^{\prime} \mathrm{N}-34^{\circ} 25^{\prime} \mathrm{N}\right)$ is located in the north of Jiangsu province, China (Figure 1), with an area of $8555 \mathrm{~km}^{2}$ and a population of 5.17 million. It has a warm temperate monsoon climate with yearly average temperature of $14.2^{\circ} \mathrm{C}$. The average annual precipitation and evaporation in the region are about 910.5 and $856.6 \mathrm{~mm}$, respectively.

In recent years, water scarcity has become one of the main obstacles to the social-economic development of Suqian along with the increasing water demand. In 2014, Suqian launched the public building water consumption survey program. The program targets were summarized as follows: 1) to clarify the water 


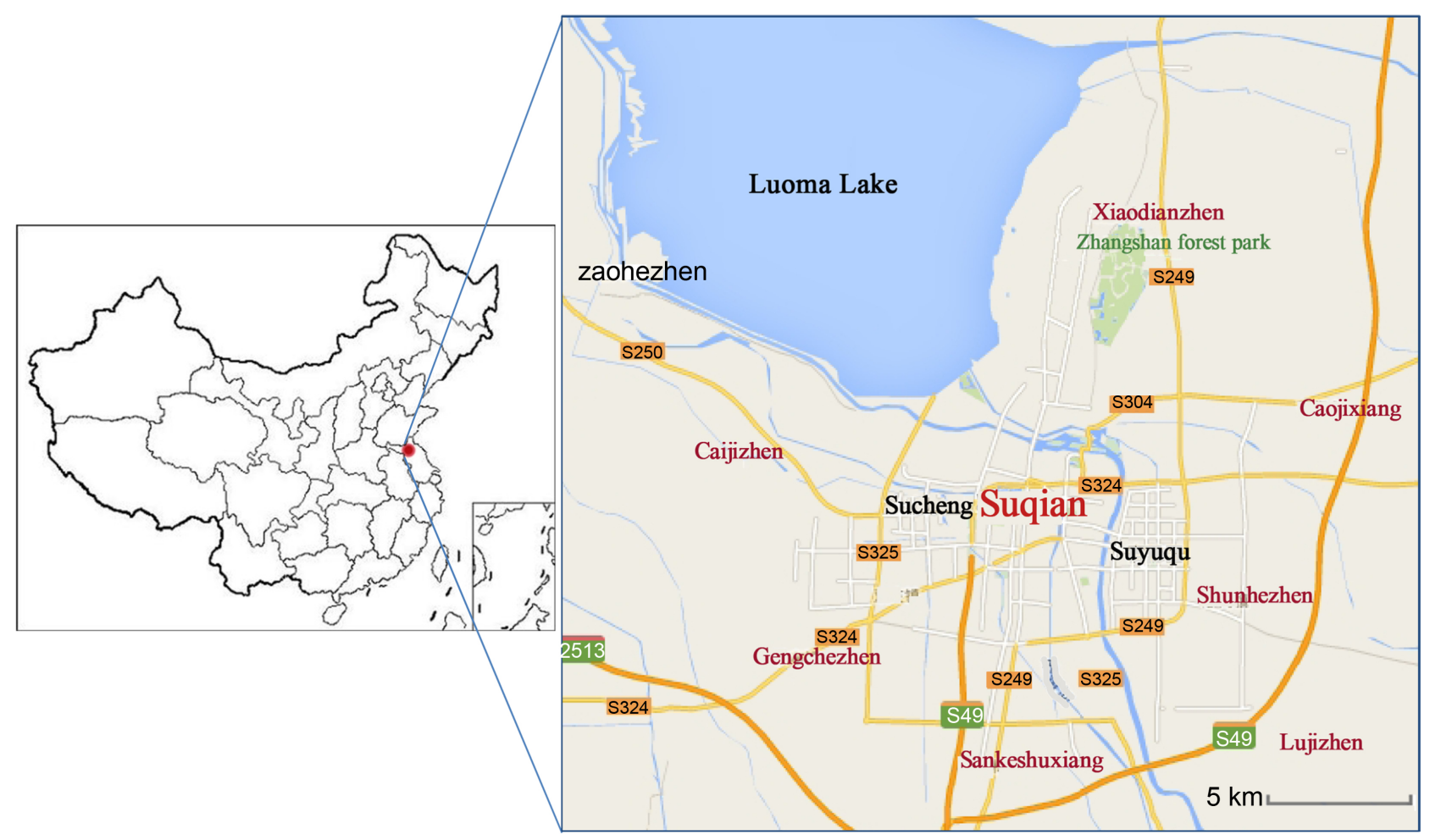

Figure 1. Location of the study area.

consumption levels in public buildings; 2) to determine the influencing factors of water consumption in buildings; 3 ) to fully study the potential water-saving measures, including technical measures and management measures; and 4) finally to provide water management departments with a list of technical measures and management measures to improve water use efficiency in public buildings.

23 high-rise public buildings in total ranging from 10 to 24 stories were surveyed in 2014, including 14 office buildings, 5 hotel buildings, and 4 hospital buildings. These buildings were selected in consideration of different use purposes, story numbers, construction years, and management levels to ensure their representativeness. A summary and comparison of different parameters for different selected buildings are listed in Table 1 .

\subsection{Water Consumption Survey Methods}

Water consumption survey and tests on field water appliance outflow characteristics were conducted from May to September 2014. The following work was conducted: 1) basic information of the buildings was collected via survey forms; 2) tests on the field outflow characteristics of water appliances were conducted on different floors of the buildings; 3) two-year monthly water consumption data of every building were collected; 4) seven-day continuous daily water consumption data were monitored in every building; and 5) two-day continuous hourly water consumption data were monitored in nine office buildings, five hotel buildings, and four hospital buildings. 
Table 1. Summary and comparison of the selected buildings.

\begin{tabular}{cccccccccccc}
\hline \multirow{2}{*}{ Items } & $\begin{array}{c}\text { Sample } \\
\text { numbers }\end{array}$ & \multicolumn{3}{c}{ Numbers of storey } & \multicolumn{3}{c}{ Floor area $\left(1000 \mathrm{~m}^{2}\right)$} & \multicolumn{3}{c}{ Building age (year) } \\
\cline { 3 - 11 } & Max. & Min. & Avg. & Max. & Min. & Avg. & Max. & Min. & Avg. \\
\hline $\begin{array}{c}\text { Office } \\
\text { building }\end{array}$ & 9 & 21 & 12 & 16.5 & 29.8 & 12.0 & 21.9 & 14 & 4 & 8.6 \\
$\begin{array}{c}\text { Hotel } \\
\text { building }\end{array}$ & 4 & 28 & 6 & 15.4 & 112.5 & 8.8 & 36.7 & 9 & 3 & 7.0 \\
$\begin{array}{c}\text { Hospital } \\
\text { building }\end{array}$ & 5 & 24 & 9 & 16.3 & 76.6 & 22.7 & 43.2 & 7 & 1 & 4.0 \\
\hline
\end{tabular}

\subsection{Field Outflow Characteristics Test Method}

The apparatus for field outflow characteristics testing of water appliance is shown in Figure 2. The pressure gauge had a measuring range of $0-1.6 \mathrm{MPa}$ with a minimum scale of $0.02 \mathrm{MPa}$ and an accuracy class of 0.25 . Outflow rate was measured using the volumetric method as follows: a known volume bucket that can contain more than $30 \mathrm{~s}$ of outflow was used as a container. The time to fill up the bucket was recorded during the test, hence, average flow rate could be determined by dividing the volume by the recorded time. The aim of the test was to obtain the real outflow rate of different types of faucets under different pressures and then quantitatively assess water wastage due to OPO. To the single lever basin tap, the outflow characteristics of half open (turn on $45^{\circ}$ ) and full open (turn on $90^{\circ}$ ) were tested. Test were conducted during the periods of 9:00 am - 10:30 am and 2:00 pm - 5:00 pm to avoid the water consumption peak hours, which would make the water pressure unstable. The index of OPO rate was used to quantitatively reflect how universal the OPO was. OPO rate is defined as the percentage of testing points with outflow rate higher than $0.15 \mathrm{~L} / \mathrm{s}$ in all the testing points.

\subsection{Branch Pipe Pressure Reducing Test Apparatus}

To further study the outflow law of different water appliances under different pressures and quantitatively assess the water-saving potential of branch pipe pressure-reducing measures, a branch pipe pressure control test apparatus was established in the building water supply and drainage laboratory at Nanjing Tech University (Figure 3). A centrifugal submersible pump with a rated flow of $10 \mathrm{~m}^{3} / \mathrm{h}$ and a rated head of $60 \mathrm{~m}$ was used for the test. An Amico Y22X-16T adjustable PRVs was used to obtain different pressures at the testing points, and a rotor water meter with an accuracy of $0.1 \mathrm{~L}$ was used to measure flow volume. All the tested faucets were purchased from top brand manufacturers. Commonly used single lever basin taps were tested under half open and full open conditions. In addition, some new single lever basin taps have a flow strainer at its outlet, while most old type single lever basin taps without flow strainer are still in use in buildings. Therefore, these two types of single lever basin taps were tested individually. Pressure-outflow characteristics of other commonly used water appliances, such as water basin mixer tap and shower head, were also tested. Flow 

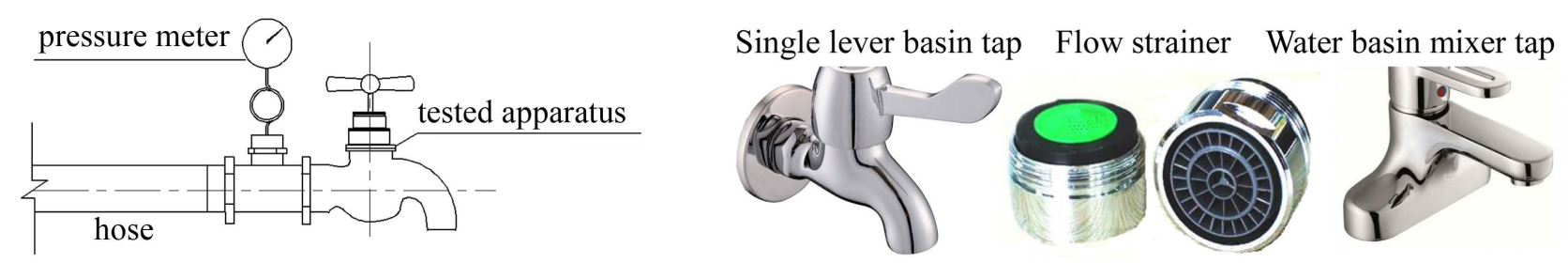

Figure 2. Field water appliances outflow characteristics testing apparatus.

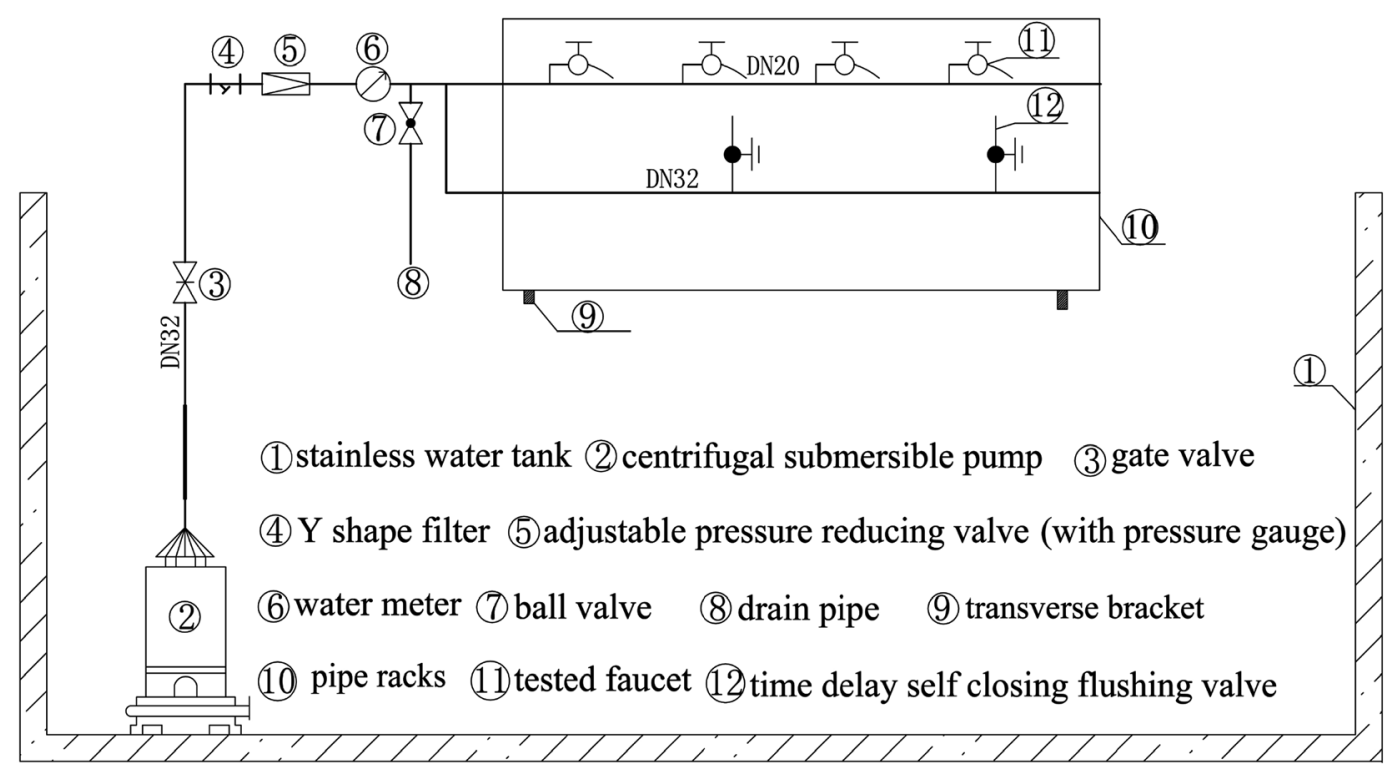

Figure 3. Branch pipe pressure reducing test apparatus.

rate of the tested faucets could be calculated via dividing flow volume recorded on the water meter by the corresponding time.

\section{Results and Discussion}

\subsection{High-Rise Public Building Water Consumption Analysis}

PCWC and its variation range can be achieved based on the two-year monthly water consumption data of the nine office buildings, five hotel buildings, and four hospital buildings from 2012 to 2013 (as shown in Figure 4). According to the recommended office building water consumption norm of $50 \mathrm{~L} \mathrm{capita}^{-1}$ shift ${ }^{-1}$ in the Chinese national standard "Code for Design of Building Water Supply and Drainage (GB 50015-2003, 2009 edition)," 64.6\% of the office building water consumption data exceeded the norm. This excess water consumption is mainly due to wastage in use, because no individual user is asked to pay for the water consumption in office buildings, hence, people pay little attention to water saving in public buildings. In addition, another possible reason that has always been neglected is the visitors in office buildings. PCWC is calculated via dividing the overall water consumption by the fixed office staff without considering visitors, which results in the calculated PCWC being higher than the real PCWC. For instance, the samples 3, 8, and 9 in Figure 4(a) are all government 

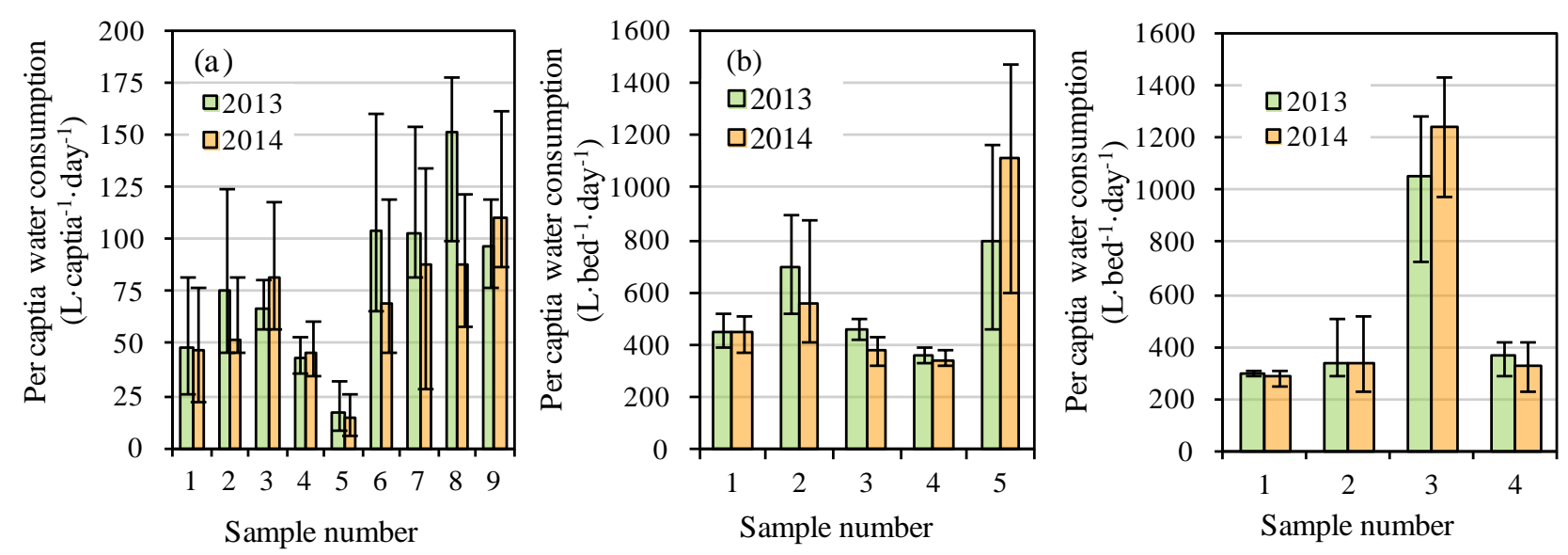

Figure 4. Per-capita water consumption in public buildings. (a) Office buildings ; (b) Hotel buildings; (c) Hospital buildings.

office buildings. These buildings have many visitors every day, hence, its calculated PCWC is much higher than the water consumption norm. Therefore, we suggest that water used by visitors should be considered in designing office building water supply systems in the future. The water consumption norm is 600 $\mathrm{L} \cdot \mathrm{bed}^{-1} \cdot \mathrm{day}^{-1}$ for three-star hotels, $800 \mathrm{~L} \cdot \mathrm{bed}^{-1} \cdot \mathrm{day}^{-1}$ for hotels with more than three-stars, and $600 \mathrm{~L} \cdot \mathrm{bed}^{-1} \cdot \mathrm{day}^{-1}$ for hospital wards with toilets. However, $15 \%$ of the water consumption in the 120 surveyed hotel building testing points exceeded the hotel water consumption norm, and $25 \%$ of the water consumption in the 96 surveyed hospital building testing points exceeded the hospital ward water consumption norm. Generally, PCWC in public buildings is much higher than the average local household water consumption of $152.4 \mathrm{~L} \cdot \mathrm{capita}^{-1} \cdot$ day $^{-1}$, suggesting that considerable water saving potential exists in these public buildings.

Hourly water consumption variation law is an important factor that should be considered in making building water supply schemes and designing the volume of the regulating structure. Hourly water consumption variation coefficient is defined as the maximum hourly water consumption versus average hourly water consumption in a day. This coefficient is also an important influencing factor in the energy-saving performance of the system. Based on the two-day continuous hourly water consumption data in nine office buildings, four hotel buildings, and four hospital buildings, the hourly water consumption ratios and its variation ranges are presented in Figure 5. Results show that obvious differences existed among different type of buildings, the hourly water consumption variation coefficient ranges for office buildings, hotel buildings, and hospital buildings are (2.14 - 3.03), (1.78 - 2.12), and (1.50 - 1.93) with an average of 2.6, 1.96, and 1.69, respectively. The variation coefficient of office buildings is the highest, suggesting that hourly water consumption in office buildings is more varied and scattered. Water use in office buildings is mainly concentrated from 7:00 am to 8:00 $\mathrm{pm}$, while water consumption in most of the surveyed office buildings approach zero during 7:00 pm to 9:00 am. The hourly water consumption variation coefficient of hotel buildings and hospital buildings are comparatively low. In particular, hourly water consumption data of hospital buildings are quite even during 

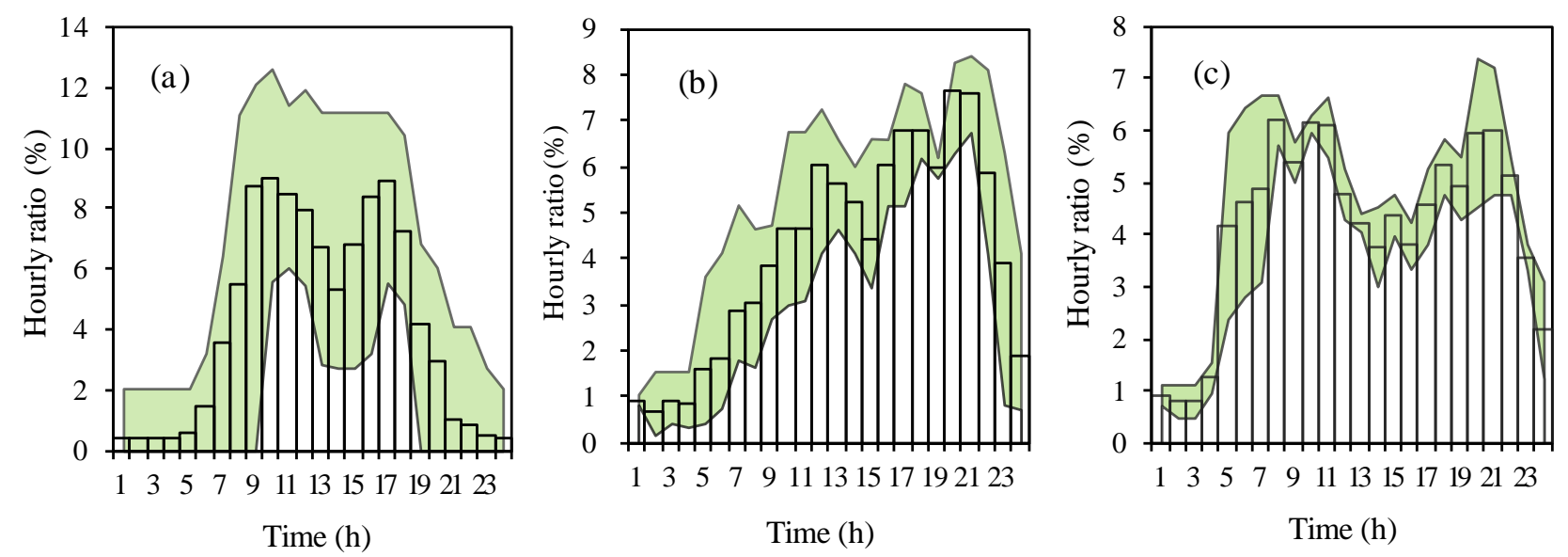

Figure 5. Hourly water consumption variation in public buildings. (a) Office buildings; (b) Hotel buildings; (c) Hospital buildings.

5:00 am to 11:00 pm. The difference in hourly water consumption is related to construction cost and energy consumed in a water supply scheme decision-making. Some research has been done on this [22] [29] [30]. In short, differences in water consumption variation law of various types of building should be considered in the water supply scheme selection to ensure the safety of the water supply systems and save energy consumed in building water supply systems.

\subsection{Factors Influencing Water Consumption in Public Buildings}

From the survey results, significant differences in PCWC existed even among the same types of buildings. Generally, use purpose, building height, per capita building area, tap water pressure, water-saving performance of appliances, and building age could all influence water consumption in buildings. To further study the influencing factors of water consumption, 12 office buildings, including government office buildings, commercial office buildings, and unit office buildings were selected to conduct correlation analysis.

As shown in Figure 6, correlation analysis indicates that obvious differences of PCWC existed among office buildings with different use purposes. This differences are mainly attributed to the quantity of visitors (Figure 6(a)). Given the nature of public service of government office buildings, they have the highest number of visitors every day, thereby the highest PCWC. In addition, the larger the per capita building area, the more water is required to clean and maintain public facilities, such as central air-conditioning system (Figure 6(b)). High tap water pressure could result in water wastage because of OPO which undoubtedly increases the PCWC (Figure 6(c)). In terms of building age, the PCWC had a positive correlation with it (Figure 6(d)). It is easy to understand that an aged water supply system suffered from problems of leakage and internal corrosion of the water appliances. In addition, the water-saving performance of water appliances in old buildings is generally not as good as that used in new buildings, which will results in the increase of PCWC with the increasing building age 


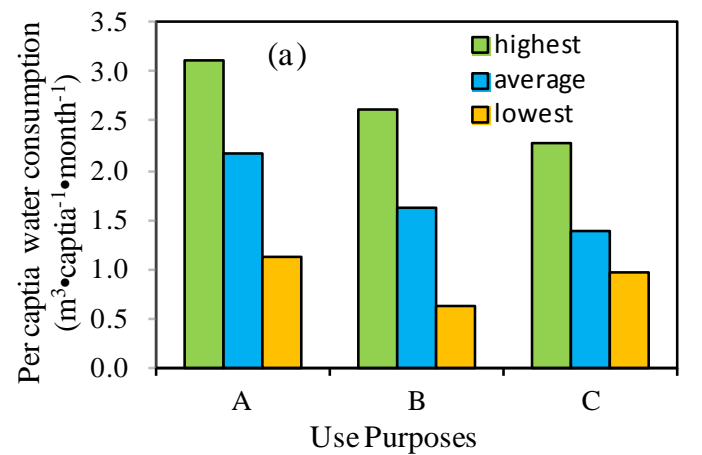

A: goverment office building; B: commercial office building; C: self-built office building

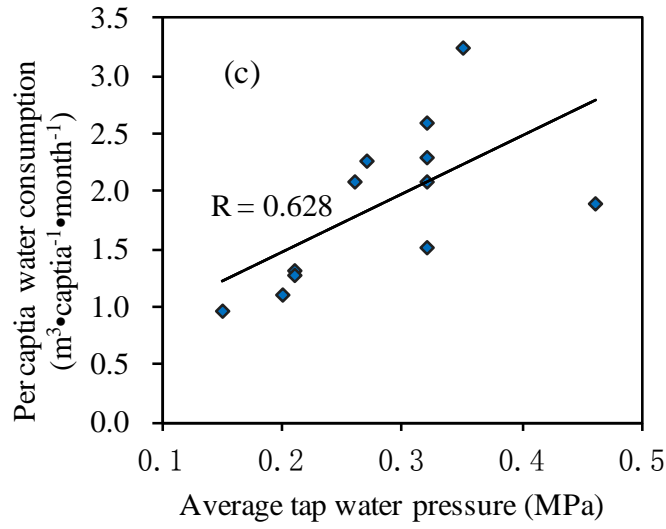

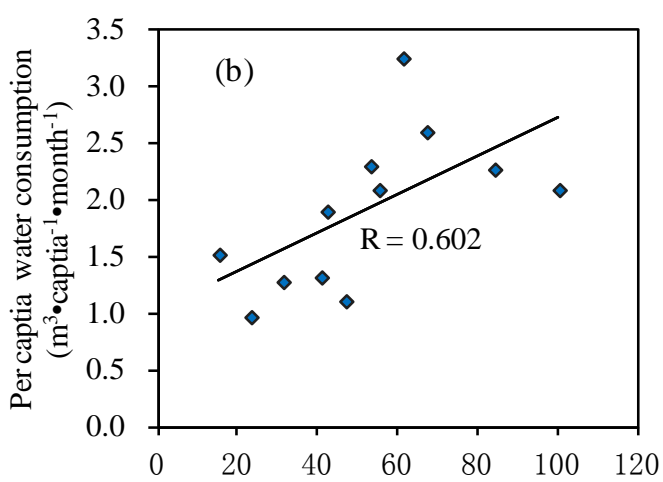

Per captia building area $\left(\mathrm{m}^{2}\right)$

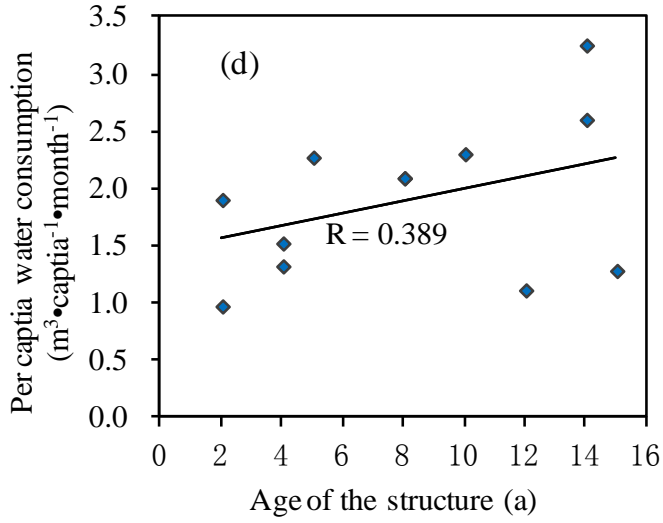

Figure 6. Correlation between per-capita water consumption and influencing factors (based on the monthly water consumption data in the 9 office buildings). (a) Influence of use purpose; (b) Influence of per-capita building area; (c) Influence of average tap water pressure; (d) Influence of building age.

(Figure 6(d)). Therefore, proper maintenance should be taken regularly to fix or replace the old plumbing systems and water appliances to save water in aged buildings. Except for the difference among different use purposes, according to the $\mathrm{R}$ value of correlation analysis, the degree sequence of influencing factors is listed as follows: average tap water pressure $>$ per-capita building area $>$ building age. Therefore, pressure management measures in high-rise buildings should be given priority consideration for water saving.

\subsection{Water Appliances Outflow Characteristics Field Tests}

As discussed in section 3.2, tap water pressure is an important factor influencing the water consumption of buildings, especially for high-rise buildings. However, Field test results on outflow characteristics of the tested faucets were scattered (Figure 6), only some statistic laws could be achieved due to the variance in age of the pipe structure, the diameter of distribution pipe, and the corrosion degree of the faucets. To further study the correlation of water pressure on the outflow characteristics of water appliances, single lever basin taps and water basin mixer taps in 23 investigated buildings were tested. The scattergram of test results are depicted in Figure 7, except for the single lever basin tap without flow strainer, the tested faucets under the pressure of $\leq 0.1 \mathrm{MPa}$ met the maximum outflow 

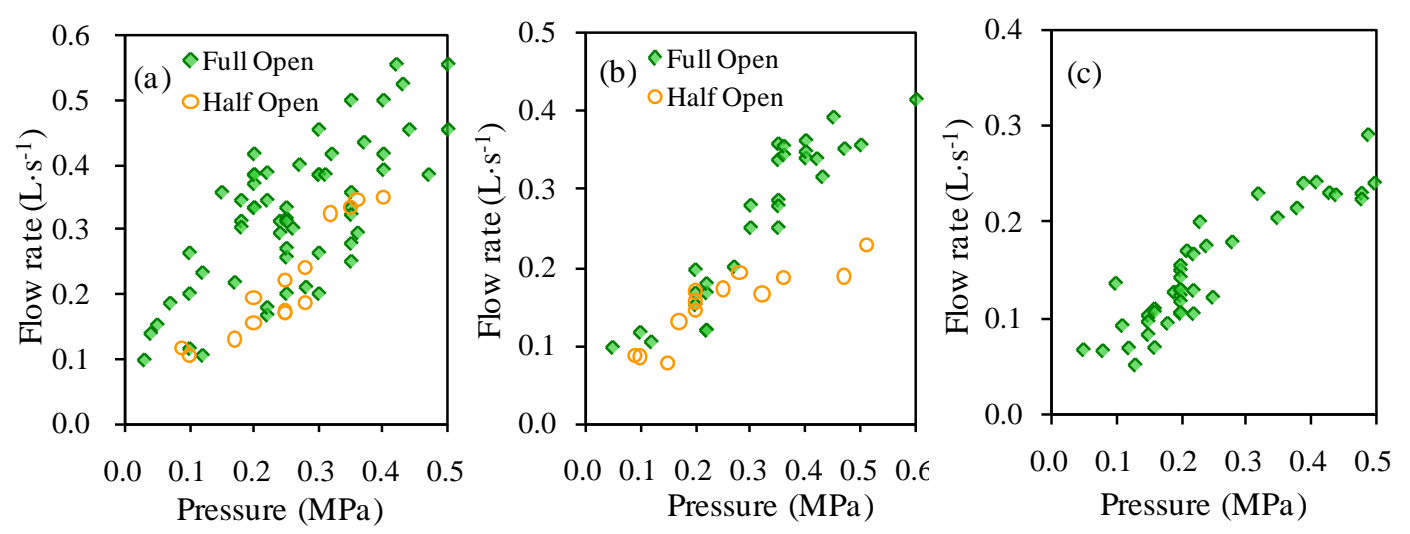

Figure 7. Field test of outflow characteristics of faucet under different pressure. (a) Single lever basin tap without flow strainer; (b) Single lever basin tap with flow strainer; (c) Water basin mixer tap.

rate limitation of $0.15 \mathrm{~L} / \mathrm{s}$. However, water pressure of more than $95 \%$ of the tested points were higher than $0.1 \mathrm{MPa}$ while more than $64.5 \%$ exceeded 0.2 MPa stated in GB50555-2010 and more than $12 \%$ even exceeded $0.45 \mathrm{MPa}$, the maximum pressure limitation recommended in GB50015-2003 (2009 edition). Obviously, OPO is common in these buildings, it could results in severe water wastage. Further analysis indicates that OPO rate of single lever basin tap without flow strainer reached as high as $93.22 \%$ under the full open condition and $78.6 \%$ under the half-open condition (Figure $7(\mathrm{a})$ ). For single lever basin tap with flow strainer, the highest OPO rate was $79.3 \%$ under full open and $69.2 \%$ under half open (Figure $7(\mathrm{~b})$ ). The above results indicate that single lever basin taps without a flow strainer cannot meet the standards for water-saving faucets and induce severe water wastage. Therefore, it should be replaced by high-efficiency faucets in existing buildings. Compared with single lever basin taps, the OPO rate of water basin mixer taps was just $38.1 \%$. On average, their outflow rates exceeded $0.15 \mathrm{~L} / \mathrm{s}$ only under water pressure exceeding $0.28 \mathrm{Mpa}$ (Figure $7(\mathrm{c})$ ). Given the above results, OPO should be given considerable attention. For example, in a 22-storey government office buildings, the original frequency conversion variable speed pump water supply system was abandoned because of improper management. Then, the system was reconstructed into a constant speed pump and roof tank system. Water was distributed from the roof tank to different stories from the top floor to the ground floor without any pressure-reducing measure on the main pipe. This design scheme caused the water pressure on the ground floor to reach as high as $0.7 \mathrm{MPa}$ and resulted in severe $\mathrm{OPO}$, water splash, water wasting and uncomfortableness of water use.

\subsection{Laboratory Tests on Water-Saving Performance of Branch Pipe Pressure-Reducing Measure}

As shown in Figure 7, the outflow characteristics of the same type of faucets were different even under the same pressure because of the variance in brand, age of use, and degree of corrosion. Therefore, in order to confirm the efficiency 
of branch pipe pressure-reducing measures and obtain the exact law between water pressure and outflow characteristics laboratory experiments were conducted and the results (Figure 8) are discussed as follows.

The Chinese national standard "Minimum allowable values of water efficiency and water efficiency grades for faucets (GB 25501-2010)" requires that the minimum water efficiency grade for faucet is grade III with a maximum outflow rate of $0.15 \mathrm{~L} / \mathrm{s}$ under a dynamic pressure of $0.1 \pm 0.01 \mathrm{MPa}$. Meanwhile, the grade for water saving faucets should reach II with a maximum outflow rate of 0.125 $\mathrm{L} / \mathrm{s}$ under a dynamic pressure of $0.1 \pm 0.01 \mathrm{MPa}$. American standard "ASME A112.18.1-2005/CSA B125.1-05 Plumbing Supply Fittings" requires the maximum flow rate of shower heads to be $9.5 \mathrm{~L} / \mathrm{min}(0.158 \mathrm{~L} / \mathrm{s})$, whereas the Chinese national code of "Domestic water saving devices (CJ 164-2014)" requires the maximum flow rate of showerheads to be $0.12 \mathrm{~L} / \mathrm{s}$. As can be seen in Figure 8, the relationship between outflow rate of faucet and water pressure generally follows the exponential law. The outflow rate of single lever basin tap without flow strainer was $0.195 \mathrm{~L} / \mathrm{s}$ under the pressure of $0.1 \mathrm{MPa}$, suggesting that it can not meet the standard for water-saving faucets. By the contrast, the outflow rate of single lever basin tap with flow strainer was lower than $0.15 \mathrm{~L} / \mathrm{s}$ under the pressure of $0.1 \mathrm{MPa}$. Therefore, a flow strainer at the faucet outlet can effectively improve the stability and reduce the volume of outflow. However, both of them
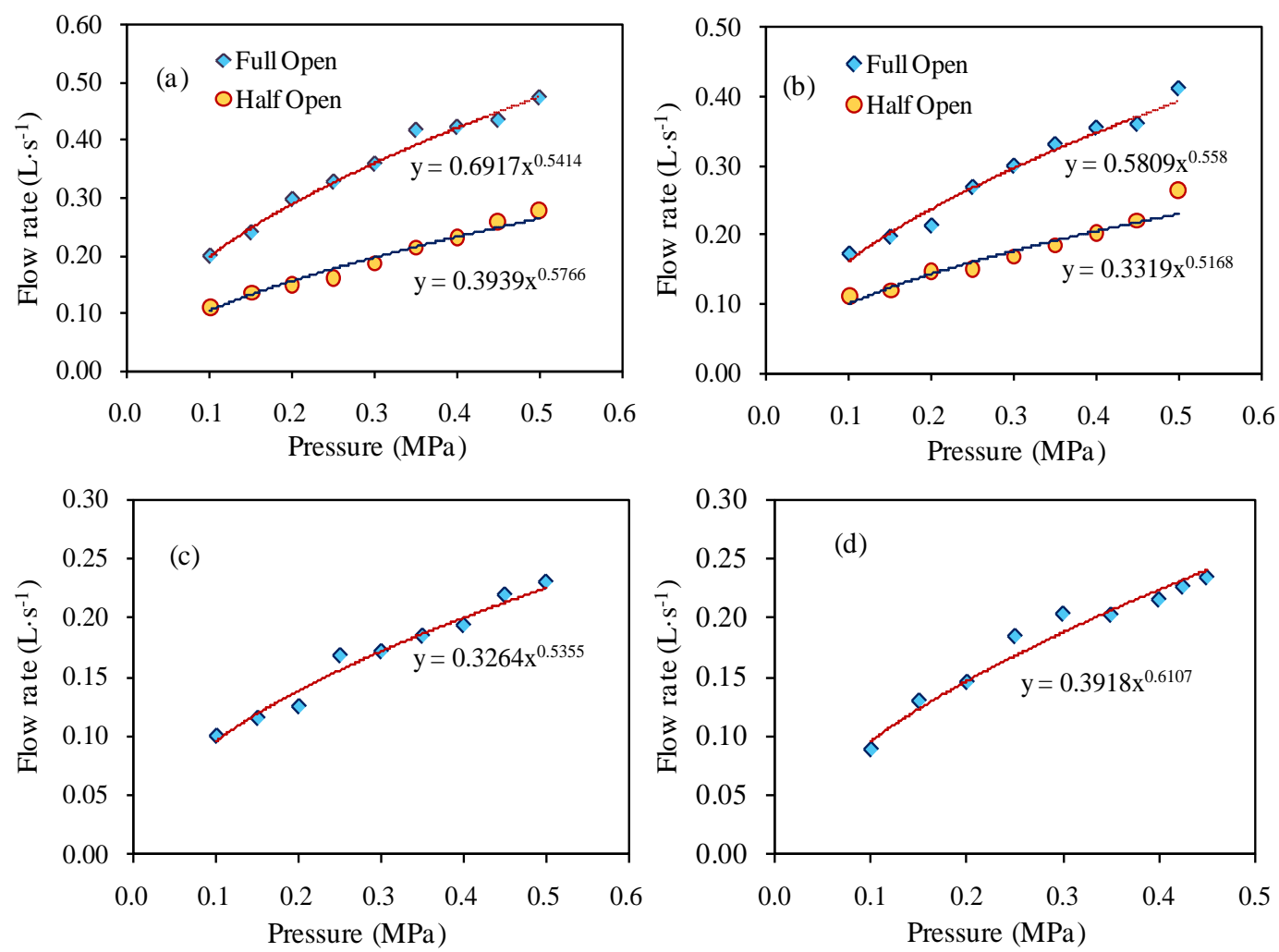

Figure 8. Laboratory test of outflow characteristics of faucet under different pressure. (a) Single lever basin tap without flow strainer; (b) Single lever basin tap with flow strainer; (c) Water basin mixer tap; (d) Shower head. 
faced the problem of OPO under high pressure. For instance, under the maximum pressure of $0.5 \mathrm{MPa}$, the outflow rate of single lever basin tap without flow strainer reached $0.510 \mathrm{~L} / \mathrm{s}$ under the full open condition and $0.310 \mathrm{~L} / \mathrm{s}$ under the half open condition (Figure 8(a)). Once the pressure on the faucet was reduced to $0.2 \mathrm{MPa}$ by adjusting the PRV on branch pipe, its flow rate reduced to 0.213 $\mathrm{L} / \mathrm{s}$ under the full open condition and $0.147 \mathrm{~L} / \mathrm{s}$ under the half open condition. By reducing pressure from $0.5 \mathrm{MPa}$ to $0.2 \mathrm{MPa}, 58.2 \%$ of the outflow rate under full open condition and $52.6 \%$ under half-open condition can be saved. The water-saving effect by reducing pressure from other values to $0.2 \mathrm{MPa}$ can also be calculated via the empirical equations shown in Figure $8(\mathrm{~b})$. The pressure-outflow rate curve of water basin mixer tap was comparatively gentle, which suggests that it has good water-saving performance. The outflow rate only reached $0.240 \mathrm{~L} / \mathrm{s}$ under the maximum testing pressure of $0.5 \mathrm{MPa}$. Once the pressure on the faucet was reduced to $0.2 \mathrm{MPa}$ by adjusting the adjustable PRVs, its flow rate decreased to $0.125 \mathrm{~L} / \mathrm{s}$, which is $37.5 \%$ of the outflow that can be saved simultaneously. Its water-saving effect by reducing pressure from other values to $0.2 \mathrm{MPa}$ can also be calculated according to the empirical fitting equations shown in Figure 8(c). From the pressure-outflow rate curve shown in Figure $8(\mathrm{~d})$, the flow rate of the shower head exceeded the maximum limitation in China under a pressure higher than $0.13 \mathrm{MPa}$ and exceeded the maximum limitation of required in the United States and Canada under a pressure higher than 0.22 MPa.

Overall, reducing water pressure at distribution point by branch pipe pressure reducing measures is an effect way for saving water in high-rise buildings; meanwhile, this will improve the comfortability of water use.

\section{Conclusion}

Water consumption survey and field water appliances outflow characteristics tests were conducted in 23 high-rise building in Suqian, China. Survey results show that PCWC exceed water consumption norm is a common phenomenon in all the surveyed buildings. Hourly water use variation law was quite different among different types of buildings, therefore, these differences should be taken into consideration in designing water supply system to lower water and energy consumption in buildings. Water consumption influencing factors follows the sequence of average tap water pressure, per-capita building area, building age, suggesting that pressure management in high building is an important water saving measure. However, no branch pipe pressure control measures were adopted in all the surveyed building. Field tests of outflow characteristics under different water pressure show that OPO is one of the main causes which lead to water wastage in buildings. Branch pipe pressure reducing measures can greatly reduce water consumption in buildings and improve the comfortability of use as well. Therefore, except for the adoption of high performance water saving appliances, we strongly suggested that branch pipe pressure reducing measures 
should be implemented in designing water supply system for new building and in reconstruction of water supply system in existing old buildings, thereby, promoting water saving and development of green building.

\section{References}

[1] Asif, M., Muneer, T. and Kelley, R. (2007) Life Cycle Assessment: A Case Study of a Dwelling Home in Scotland. Building and Environment, 42, 1391-1394.

https://doi.org/10.1016/j.buildenv.2005.11.023

[2] Arena, A. and De Rosa, C. (2003) Life Cycle Assessment of Energy and Environmental Implications of the Implementation of Conservation Technologies in School Buildings in Mendoza-Argentina. Building and Environment, 38, 359-368. https://doi.org/10.1016/S0360-1323(02)00056-2

[3] Friedler, E. and Hadari, M. (2006) Economic Feasibility of On-Site Greywater Reuse in Multi-Storey Buildings. Desalination, 190, 221-234. https://doi.org/10.1016/j.desal.2005.10.007

[4] Liu, B., Yao, Z. and Gao, Y. (2003) Trend and Driving Forces of Water Consumed Structure Changes in Beijing. Resources Science, 25, 38-43.

[5] Cheng, C.L. (2003) Evaluating Water Conservation Measures for Green Building in Taiwan. Building and Environment, 38, 369-379. https://doi.org/10.1016/S0360-1323(02)00062-8

[6] Wong, J., Jiang, Y. and Chen, Y. (2007) Present Status, Problems and Counter Measures of Public Domestic Water Consumption in Beijing. China Water \& Wastewater, 23, 77-82. (In Chinese)

[7] Zhao, J. and Jiang, H. (2009) Water Consumption Survey and Over-Pressure Outflow Field Test in High-Rise Office Buildings. Water \& Wastewater Engineering, 35, 193-195. (In Chinese)

[8] Proença, L.C. and Ghisi, E. (2012) Assessment of Potable Water Savings in Office Buildings Considering Embodied Energy. Water Resources Management, 27, 581-599. https://doi.org/10.1007/s11269-012-0203-1

[9] Lee, M., Tansel, B. and Balbin, M. (2013) Urban Sustainability Incentives for Residential Water Conservation: Adoption of Multiple High Efficiency Appliances. Water Resources Management, 27, 2531-2540. https://doi.org/10.1007/s11269-013-0301-8

[10] Aladenola, O.O. and Adeboye, O.B. (2010) Assessing the Potential for Rainwater Harvesting. Water Resources Management, 24, 2129-2137. https://doi.org/10.1007/s11269-009-9542-y

[11] Zhang, X.Q., et al. (2012) Urban Rainwater Utilization and Its Role in Mitigating Urban Waterlogging Problems-A Case Study in Nanjing, China. Water Resources Management, 26, 3757-3766. https://doi.org/10.1007/s11269-012-0101-6

[12] Ishaku, H.T., Majid, M.R. and Johar, F. (2011) Rainwater Harvesting: An Alternative to Safe Water Supply in Nigerian Rural Communities. Water Resources Management, 26, 295-305. https://doi.org/10.1007/s11269-011-9918-7

[13] Mourad, K.A., Berndtsson, J.C. and Berndtsson, R. (2011) Potential Fresh Water Saving using Greywater in Toilet Flushing in Syria. Journal of Environmental Management, 92, 2447-2453.

[14] Santos, C., et al. (2012) Development of an Experimental System for Greywater Reuse. Desalination, 285, 301-305.

[15] Ahmad, S. and Prashar, D. (2010) Evaluating Municipal Water Conservation Poli- 
cies Using a Dynamic Simulation Model. Water Resources Management, 24, 3371-3395. https://doi.org/10.1007/s11269-010-9611-2

[16] Fidar, A., Memon, F. and Butler, D. (2010) Environmental Implications of Water Efficient Microcomponents in Residential Buildings. Science of the Total Environment, 408, 5828-5835.

[17] Lee, M., Tansel, B. and Balbin, M. (2011) Influence of Residential Water Use Efficiency Measures on Household Water Demand: A Four Year Longitudinal Study. Resources, Conservation and Recycling, 56, 1-6.

[18] Millock, K. and Nauges, C. (2010) Household Adoption of Water-Efficient Equipment: The Role of Socio-Economic Factors, Environmental Attitudes and Policy. Environmental and Resource Economics, 46, 539-565. https://doi.org/10.1007/s10640-010-9360-y

[19] Beal, C., et al. (2011) SEQ Residential End Use Study. Journal of the Australian Water Association, 38, 80-84.

[20] Plappally, A. (2012) Energy Requirements for Water Production, Treatment, End Use, Reclamation, and Disposal. Renewable and Sustainable Energy Reviews, 16, 4818-4848.

[21] Cheng, C.L. (2002) Study of the Inter-Relationship between Water Use and Energy Conservation for a Building. Energy and Buildings, 34, 261-266.

[22] Cheung, C.T., Mui, K.W. and Wong, L.T. (2013) Energy Efficiency of Elevated Water Supply Tanks for High-Rise Buildings. Applied Energy, 103, 685-691.

[23] Ghisi, E., Rupp, R.F. and Triska, Y. (2014) Comparing Indicators to Rank Strategies to Save Potable Water in Buildings. Resources, Conservation and Recycling, 87, 137-144.

[24] Rahman, A., Keane, J. and Imteaz, M.A. (2012) Rainwater Harvesting in Greater Sydney: Water Savings, Reliability and Economic Benefits. Resources, Conservation and Recycling, 61, 16-21.

[25] Ward, S., Memon, F. and Butler, D. (2012) Performance of a Large Building Rainwater Harvesting System. Water Research, 46, 5127-5134.

[26] Farreny, R., Gabarrell, X. and Rieradevall, J. (2011) Cost-Efficiency of Rainwater Harvesting Strategies in Dense Mediterranean Neighbourhoods. Resources, Conservation and Recycling, 55, 686-694.

[27] Lee, M., Tansel, B. and Balbin, M. (2011) Goal Based Water Conservation Projections Based on Historical Water Use Data and Trends in Miami-Dade County. Sustainable Cities and Society, 1, 97-103.

[28] Fu, W. and Liu, J. (2002) Situation and Measures beyond Over-Pressure Outlet in Building Water Supply System. Water \& Wastewater Engineering, 28, 48-51. (In Chinese)

[29] Xu, Y. and Zhang, X. (2012) Research on Pressure Optimization Effect of High Level Water Tank by Drinking Water Network Hydraulic Model. Procedia Engineering, 31, 958-966.

[30] Jiang, L., Chen, Y. and Fan, G. (2011) The Design of Constant Pressure Water Supply System Based on ABB Inverter. Procedia Engineering, 15, 436-442. 
Submit or recommend next manuscript to SCIRP and we will provide best service for you:

Accepting pre-submission inquiries through Email, Facebook, LinkedIn, Twitter, etc. A wide selection of journals (inclusive of 9 subjects, more than 200 journals)

Providing 24-hour high-quality service

User-friendly online submission system

Fair and swift peer-review system

Efficient typesetting and proofreading procedure

Display of the result of downloads and visits, as well as the number of cited articles Maximum dissemination of your research work

Submit your manuscript at: http://papersubmission.scirp.org/

Or contact gep@scirp.org 